\title{
MDR1 Haplotypes Modify BEN Disease Risk: A Study in Bulgarian Patients with Balkan Endemic Nephropathy Compared to Healthy Controls
}

\author{
S. Atanasova ${ }^{a}$ N. von Ahsen ${ }^{c} \quad$ T. Dimitrov ${ }^{b} \quad$ V. Armstrong ${ }^{c} \quad$ M. Oellerich ${ }^{c}$ \\ D. Toncheva ${ }^{a}$
}

Departments of a Medical Genetics and ${ }^{\mathrm{b} N e p h r o l o g y, ~ M e d i c a l ~ U n i v e r s i t y, ~ S o f i a, ~ B u l g a r i a ; ~}$

'Department of Clinical Chemistry, Georg August University, Göttingen, Germany

\section{Key Words}

MDR1 - Balkan endemic nephropathy · Bulgarian

population $\cdot$ SNP analysis $\cdot$ Haplotyping

\begin{abstract}
Background: Balkan endemic nephropathy (BEN) is a slow progressive nephropathy with frequent occurrence of uroepithelial tumors in the upper urinary tract. Genetic factors involved in xenobiotic detoxification mechanisms may cause genetic predisposition to BEN and influence the risk for this disease. Polymorphic MDR1 variants with decreased $\mathrm{P}$-glycoprotein (P-gp) activity modulate the risk for renal neoplasm. We have therefore investigated the impact of MDR1 polymorphisms on BEN manifestation. Methods: The constitutional genotype frequencies of two SNPs (C3435T and G2677T) in the MDR1 gene in 112 healthy control subjects were investigated and compared with those of 96 patients with BEN. Identification of the SNPs was done with rapid cycle real-time PCR and melting curve analysis with allele-specific probes. Results: The frequency of mutant
\end{abstract}

The authors wish it to be known that, in their opinion, S.A. and N.v.A. should be regarded as joint first authors. alleles was comparable in both groups. Significant differences were revealed when the MDR1 haplotypes were analyzed. Individuals with a predicted haplotype 12 $(2677 \mathrm{G} / 3435 \mathrm{~T})$ were less frequent in BEN cases (frequency $7.3 \%$ ) than in controls $(16.1 \%, p=0.006)$. We found that carriers of the haplotype 12 had a decreased risk for BEN (OR $=0.411 ; 0.21-0.78)$. Conclusions: The data suggest that haplotype 12 is protective against BEN. There is no clear molecular explanation of the MDR1 haplotype effects on the protein activity, which can explain the modified effect of the haplotype 12 on BEN risk.

Copyright $\odot 2004$ S. Karger AG, Basel

\section{Introduction}

Balkan endemic nephropathy (BEN) is a slow progressive nephropathy. A high incidence of epithelial tumors of the upper urinary tract is observed in BEN patients [1]. The functional investigation of the kidney at early stages of BEN revealed more pronounced damage in tubular than in glomerular function. At the end stage, the disease shows severe alterations in the external renal cortex and bilaterally shrunken kidneys [2].

BEN has an expressed familial character, although new incidences of disease have been described. The familial

Prof. Draga Toncheva, PhD

Department of Medical Genetics, Medical University Sofia

2 Zdrave street

BG-1431 Sofia (Bulgaria)

Tel./Fax +35929520 357, E-Mail draga@spnet.net 
inheritance has no typical pattern for Mendelian genetic inheritance, although Mihailov claimed an autosomal dominant type of transmission in 1979 [3-5]. The frequencies of BEN incidences were much higher when one or both parents were ill (respectively 15 and 39\%), compared to the frequency of cases with healthy parents $(6.5 \%)$. Individuals with first-degree relatedness with BEN patients have the highest risk (44\%) for developing BEN, compared to those with distant relationships (5\%) [6]. BEN occurs with different frequencies in different ethnic groups, which are occupant of the same endemic settlement. A great number of emigrants from endemic families in non-endemic regions, who developed endemic nephropathy, were observed, but no cases of disease among the immigrants into the endemic settlements were found in Bulgaria [2, 6].

The etiology of BEN is still unknown, in spite of the existence of several hypotheses for implications of toxic, infectious and genetic factors [6-9]. Polymorphic xenobiotic metabolizing enzymes, TGF- $\beta$, oncogenes and tumor-suppressor genes were previously proposed as candidate modifiers of BEN risk [6]. Impaired $M D R 1$ functional activity may determine higher susceptibility of BEN patients to exogenous factors. $M D R 1$ belongs to the ABCtransporter family and is associated with multidrug resistance of tumor cells to chemotherapeutic agents. Phase I and phase II detoxification enzymes and $M D R 1$ form a defense system against environmental toxins. The MDR 1 gene product $\mathrm{P}$-glycoprotein (P-gp) is normally expressed in leukocytes, central nervous system, liver, kidney and other tissues. In the kidney, P-gp was found in the brush border membrane of the proximal tubule, as well as in mesangial cells $[10,11]$. A role of P-gp for lipophilic xenobiotica secretion, including drugs, toxins and endogenous compounds, was established [12]. It is also a known compound of the renal organic cation-proton antiporter system [13].

P-gp mediates the transport of polycyclic aromatic hydrocarbons (PAH) [14]. In vitro expression of $M D R 1$ in renal cells was shown to be influenced by environmental stress from arsenite, cadmium chloride and heavy metals $[15,16]$. Modulation of P-gp levels from compounds suspected as causative factors for BEN was supposed. Some authors suggested a possible association between BEN etiology and detection of soluble PAH and aromatic amines, released from low-rank coals into the drinking water from shallow farm wells in endemic regions $[17,18]$. The mechanism of action of heavy metals in kidney remains unknown, although their strong nephrotoxic effect was established in other non-BEN nephropathies [19].
Several MDR1 mutations or combined mutations (haplotypes) determine functionally different variants among Caucasians. The wild-type allele was related to normal level of gene expression and normal activity. It determines cell resistance to drugs. In contrast, the variant alleles showed low P-gp expression and were associated with altered absorption and/or disposition profiles of P-gp-mediated drugs [20, 21]. The most frequent SNPs in MDR 1 are C3435T and G2677T. Recently, an effect of the SNP C3435T was demonstrated on the pharmacokinetics of oral digoxin, moreover a phenotype-haplotype correlation was observed [22]. Individuals carrying haplotype $12(2677 \mathrm{G} / 3435 \mathrm{~T})$ had higher values for digoxin plasma concentration [AUC 0-4 h] than non-carriers.

Furthermore, MDR 1 polymorphisms have been associated with tumor occurrence. Recently, an association between C3435T and a higher risk for different renal epithelium cancers was established. The $3435 \mathrm{~T}$ allele, especially in homozygous carriers, enhances the susceptibility to develop renal epithelial tumors [23]. Haplotypes were not investigated in that study.

Frequencies of $M D R 1$ variants in the general Bulgarian population as well as in BEN patients are not known. We proposed that different MDR1 gene variants may create genetic predisposition to xenobiotic susceptibility, because of a decreased ability to detoxify via renal excretion mechanisms. This may predispose to both the altered kidney function in BEN and manifestation of BEN-related uroepithelial tract tumors.

\section{Materials and Methods}

\section{Subjects}

We genotyped 96 non-related Bulgarian BEN patients from 9 endemic villages in the Vratza district and 112 healthy voluntary Bulgarians (controls) from non-endemic areas. Our cohort of BEN patients consisted of 21 men and 75 women (with a mean age of $63 \pm 14$ years) and is to our knowledge the largest group of nonrelated BEN patients studied to date. They were diagnosed as having BEN between September 1999 and November 2001. All patients fulfilled diagnostic criteria for BEN, place of birth and residence in an endemic village. Eleven of them had carcinoma ( 7 with renal and 4 with bladder localization). In the patient group the female predominance (3.6:1; females:males) is observed.

The controls were matched to the patient group by sex ( 84 women and 28 men; ratio $3.0: 1)$ and age ( $58 \pm 10$ years $)$ and had no history of renal and other family cancer diseases. Patients and control individuals gave their written consent to be included in this study.

\section{Genotyping}

Genomic DNA was isolated from $9 \mathrm{ml}$ whole blood by a standard DNA isolation protocol [24]. The mutations were detected using rapid-cycle real-time PCR amplification with allele-specific probes and e8

Nephron Exp Nephrol 2004;96:e7-e13
Atanasova/von Ahsen/Dimitrov/

Armstrong/Oellerich/Toncheva 

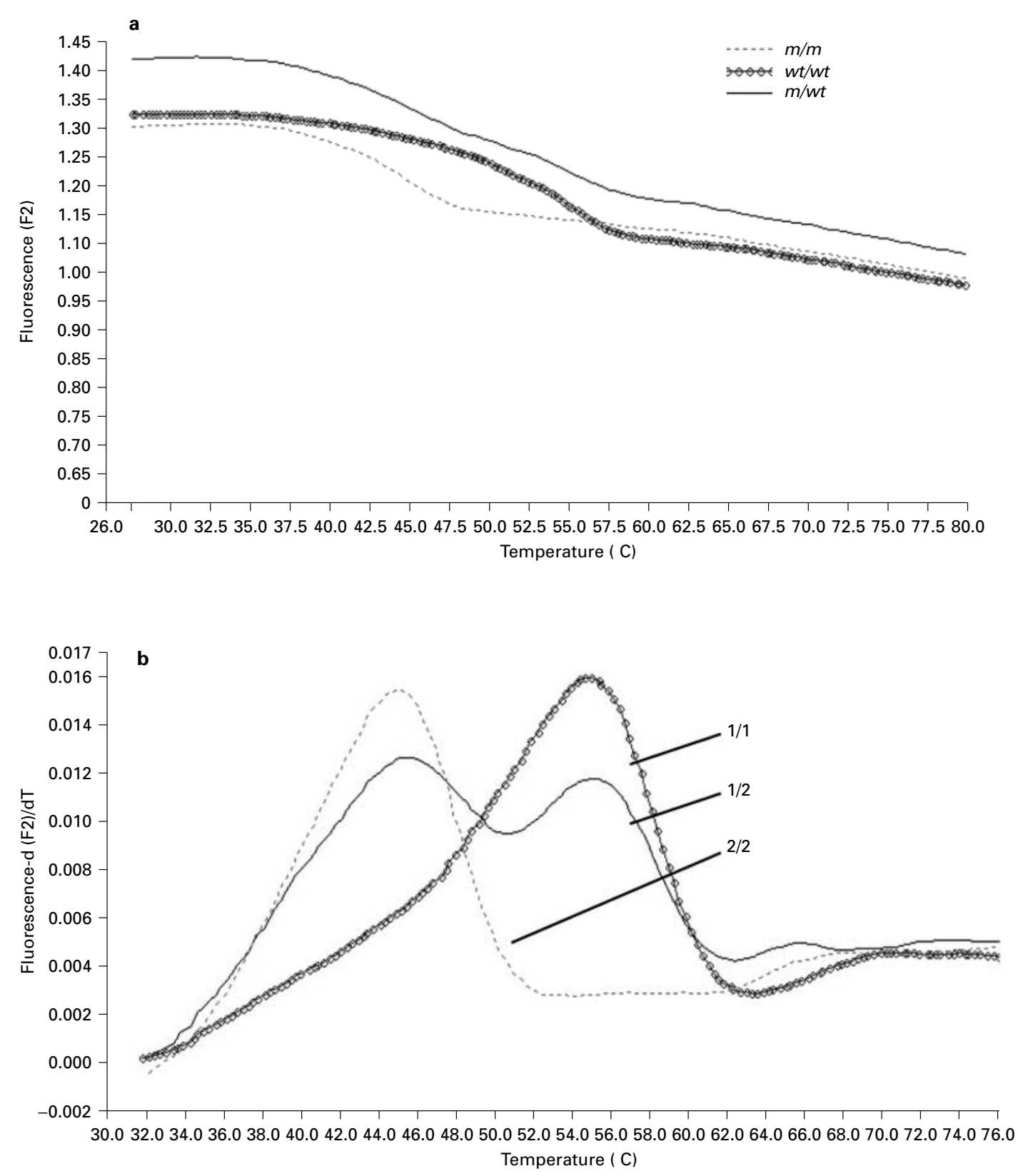

melting curve analyses. The PCR was performed on a LightCycler ${ }^{\mathrm{TM}}$ (Roche Biochemica). The C3435T mutation was identified as previously described by von Ahsen et al. [25].

The PCR primers were chosen with Primer3 (http://wwwgenome.wi.mit.edu/cgi-bin/primer/primer3_www.cgi) and hybridization probes for G2677T genotyping by the MeltCalc software for thermodynamic probe modeling (http://www.meltcalc.com) [26]. PCR mix contained $1 \mu 1$ genomic DNA $(500 \mathrm{ng} / \mu \mathrm{l}), 1 \mu \mathrm{l} 10 \times \mathrm{PCR}$ buffer (Gibco BRL), $0.5 \mu \mathrm{mol} / 1$ forward primer (5'-AGCAAATCTTGGGACAGGAAT- $3^{\prime}$ ) and $0.5 \mu \mathrm{mol} / 1$ reverse primer (5'-TCAATCATATTTAGTTTGACTCACCTT-3'), $0.2 \mu \mathrm{mol} / 1$ 5'end Rox-labeled anchor probe (5'-TCTTATCTTTCAGTGCTTGT- 
CCAGAC-3'-phosphate) and $0.2 \mu \mathrm{mol} / 1$ 3'-end fluorescein-labeled wild-type hybridization probe (5'-CCAGCACCTTCTAGTTCT-3'), $0.2 \mathrm{mmol} / \mathrm{l}$ of each dNTP, $2.5 \mathrm{mmol} / 1 \mathrm{MgCl}_{2}, 500 \mathrm{mg} / \mathrm{l}$ bovine serum albumin (New England BioLabs), $50 \mathrm{ml} / \mathrm{l}$ dimethylsulfoxide (Sigma) and $0.5 \mathrm{U} / \mu 1$ Taq DNA polymerase (Invitrogen). The amplification conditions were: 1 cycle at $95^{\circ} \mathrm{C}$ for $2 \mathrm{~min} ; 45$ cycles of denaturation at $95^{\circ} \mathrm{C}, 0 \mathrm{~s}$, ramp rate $20^{\circ} \mathrm{C} / \mathrm{s}$; annealing at $50^{\circ} \mathrm{C}, 10 \mathrm{~s}$, ramp rate $20^{\circ} \mathrm{C} / \mathrm{s}$ and extension at $72{ }^{\circ} \mathrm{C}, 20 \mathrm{~s}$, ramp rate $20^{\circ} \mathrm{C} / \mathrm{s}$. The amplified 190-bp product was denatured at $95^{\circ} \mathrm{C}$ for $20 \mathrm{~s}$, holding the reaction at $60^{\circ} \mathrm{C}$ for $20 \mathrm{~s}, 50^{\circ} \mathrm{C}$ for $20 \mathrm{~s}$, followed by a melting curve acquisition from 28 to $80^{\circ} \mathrm{C}$ at a ramp rate $0.1^{\circ} \mathrm{C} / \mathrm{s}$ in channel two. Two different peaks, corresponding to the wild-type allele (1) at $55^{\circ} \mathrm{C}$ and to the variant allele (2) at $44^{\circ} \mathrm{C}$ were observed (fig. 1).

The haplotype nomenclature was previously described by Johne et al. [22]. The haplotypes were named as follows: 11 for allele without mutations $(2677 \mathrm{G} / 3435 \mathrm{C}), 12$ for allele with $(2677 \mathrm{G} / 3435 \mathrm{~T}), 21$ for allele with $(2677 \mathrm{~T} / 3435 \mathrm{C})$ and 22 for allele carrying both mutations (2677T/3435T). Double heterozygous individuals can have two haplotype pairs, $12 / 21$ or $11 / 22$. Based on the calculated haplotype frequencies by the EH program, the occurrence of haplotype pair $11 / 22$ is much more likely than that of $12 / 21$ [27]. Accordingly, double heterozygous genotypes were bound as haplotype 11/22.

The linkage disequilibrium (LD) between the two SNPs was estimated with PM software [28, 29]. The statistical analysis was done with the $\chi^{2}$ test available on (http://quantrm2.psy.ohio-state.edu/ kris/chisq/chisq.htm). Odds ratios with calculation for confidence intervals in an unmatched case-control study were done according to Bland and Altman [30] with software available online (http:// www.hutchon.freeserve.co.uk/ConfidOR.htm), accessed 09. Sept. 2002 by D. Hutchon.

\section{Results}

We investigated the frequency of two MDR1 mutations (C3435T and G2677T) in 96 BEN patients from Vratza endemic region and 112 healthy Bulgarians to study a possible significance of $M D R 1$ gene polymorphisms in the genetic predisposition to BEN.

Epidemiological studies reported a number of SNPs in the MDR 1 gene, determining several alleles [21]. A functional significance has so far been established for the SNPs G2677T (in exon 21) and C3435T (in exon 26) [21$23,31]$. There is also evidence that haplotypes are more predictive than the underlying SNPs [22, 31].

The summarized results for the mutation frequencies among both groups are presented in table 1. The two SNPs in $M D R 1$ were identically prevalent in both studied groups but significant differences were observed when the individuals were stratified to heterozygous and homozygous genotypes. The heterozygotes (1/2) for C3435T were more prevalent in BEN patients (frequency 0.625) compared to the healthy population $(0.420)(\mathrm{p}<0.05)$, but in contrast, homozygous individuals $(2 / 2)$ were only rarely found in the patient group (frequency 0.177) compared to
Table 1. $M D R 1$ mutation frequencies in BEN patients and healthy Bulgarians

\begin{tabular}{|c|c|c|c|c|}
\hline \multirow[t]{2}{*}{ SNPs } & \multicolumn{2}{|c|}{$\begin{array}{l}\text { BEN patients } \\
(\mathrm{N}=96)\end{array}$} & \multicolumn{2}{|c|}{$\begin{array}{l}\text { Healthy Bulgarians } \\
(\mathrm{N}=112)\end{array}$} \\
\hline & $\mathrm{n}$ & frequency & $\mathrm{n}$ & frequency \\
\hline \multicolumn{5}{|l|}{ C3435T } \\
\hline Allele-2 & 94 & 0.490 & 119 & 0.531 \\
\hline Allele-1 & 98 & 0.510 & 105 & 0.469 \\
\hline \multicolumn{5}{|l|}{ Genotypes } \\
\hline$(1 / 2)$ & 60 & $0.625^{*}$ & 47 & $0.420^{*}$ \\
\hline$(2 / 2)$ & 17 & $0.177 * *$ & 36 & $0.321 * *$ \\
\hline$(1 / 1)$ & 19 & 0.198 & 29 & 0.259 \\
\hline \multicolumn{5}{|l|}{ G2677T } \\
\hline Allele-2 & 90 & 0.469 & 98 & 0.438 \\
\hline Allele-1 & 102 & 0.531 & 126 & 0.562 \\
\hline \multicolumn{5}{|l|}{ Genotypes } \\
\hline$(1 / 2)$ & 50 & 0.521 & 50 & 0.446 \\
\hline$(2 / 2)$ & 20 & 0.208 & 24 & 0.214 \\
\hline$(1 / 1)$ & 26 & 0.271 & 38 & 0.339 \\
\hline
\end{tabular}

Allele- 1 indicates the wild-type alleles, while allele- 2 indicates the variant alleles.

$\mathrm{N}=$ Number of studied individuals; $\mathrm{n}=$ number of alleles or number of heterozygous, homozygous.

$* \chi^{2}=8.727(\mathrm{p}=0.003) ; * * \chi^{2}=5.672(\mathrm{p}=0.017)$.

Table 2. Linkage of polymorphisms of $M D R 1$ between position 2677 and 3435

\begin{tabular}{lccc}
\hline $\begin{array}{l}\text { Position } \\
\text { (Genotype) }\end{array}$ & $\begin{array}{l}2677 \\
(1 / 1)\end{array}$ & $\begin{array}{l}2677 \\
(1 / 2)\end{array}$ & $\begin{array}{l}2677 \\
(2 / 2)\end{array}$ \\
\hline $3435(1 / 1)$ & $37^{\mathrm{a}}$ & 8 & 3 \\
$3435(1 / 2)$ & 22 & 74 & 11 \\
$3435(2 / 2)$ & 5 & 18 & 30 \\
\hline
\end{tabular}

a Number of individuals from both studied groups with the respective genotypes for C3435T and G2677T.

controls $(0.321)(p<0.05)$. The distribution of genotypes for G2677T was not significantly different between both groups.

The LD between both SNPs was highly significant in both groups $(p<0.000001)\left(\chi^{2}=61.27\right.$ for BEN cases and $\chi^{2}=39.41$ for the controls, respectively), but the observed linkage was incomplete (table 2).

The calculated frequencies for different haplotypes are presented in table 3 . The haplotype frequencies were sig- $\mathrm{e} 10$

Nephron Exp Nephrol 2004;96:e7-e13
Atanasova/von Ahsen/Dimitrov/

Armstrong/Oellerich/Toncheva 
Table 3. Calculated frequencies of different $M D R 1$ haplotypes in BEN patients and controls

\begin{tabular}{|c|c|c|c|c|c|c|c|}
\hline \multirow[t]{2}{*}{ Haplotype $^{\text {a }}$} & \multicolumn{2}{|c|}{$\begin{array}{l}\text { BEN patients } \\
(\mathrm{N}=96)\end{array}$} & \multicolumn{2}{|c|}{$\begin{array}{l}\text { Healthy Bulgarians } \\
(\mathrm{N}=112)\end{array}$} & \multirow[t]{2}{*}{$\mathrm{p}$ value } & \multirow[t]{2}{*}{ OR, 95\% CI } & \multirow{2}{*}{$\begin{array}{l}\text { Caucasians [ref. 22] } \\
(\mathrm{N}=687) \\
\text { frequency, } \%\end{array}$} \\
\hline & $\mathrm{n}$ & frequency, $\%$ & $\mathrm{n}$ & frequency, $\%$ & & & \\
\hline \multicolumn{8}{|l|}{ Observed } \\
\hline 11 & 88 & 45.8 & 90 & 40.2 & 0.245 & $1.259(0.85-1.86)$ & 43.3 \\
\hline 12 & 14 & 7.3 & 36 & 16.1 & $0.006^{*}$ & $0.411(0.21-0.78)$ & 13.3 \\
\hline 21 & 10 & 5.2 & 15 & 6.7 & 0.524 & $0.766(0.33-1.75)$ & 1.8 \\
\hline 22 & 80 & 41.7 & 83 & 37.0 & 0.337 & $1.213(0.82-1.80)$ & 41.6 \\
\hline \multicolumn{8}{|l|}{ Expected $^{b}$} \\
\hline 11 & 87 & 45.3 & 87 & 39.0 & 0.182 & $1.305(0.88-1.93)$ & - \\
\hline 12 & 15 & 7.8 & 39 & 17.2 & $0.004 *$ & $0.402(0.21-0.75)$ & \\
\hline 21 & 11 & 5.8 & 18 & 7.8 & 0.357 & $0.695(0.32-1.51)$ & \\
\hline 22 & 79 & 41.1 & 80 & 35.9 & 0.256 & $1.258(0.85-1.87)$ & \\
\hline \multicolumn{8}{|c|}{ a The haplotype nomenclature is according by Johne et al. [22]. } \\
\hline \multicolumn{8}{|c|}{ b Calculated by EH program. } \\
\hline \multicolumn{8}{|c|}{ * Statistically significant. } \\
\hline $\mathrm{N}=\mathrm{Num}$ & & studied indivi & & umber of haplc & & & \\
\hline
\end{tabular}

nificantly different among cases and controls $\left(\chi^{2}=8.12\right.$, $\mathrm{p}=0.04)$. We also compared the haplotype frequencies of BEN patients and Bulgarian healthy controls with those reported for a German Caucasian population $(n=687)$ [22]. Both groups showed also significantly different haplotype frequencies $\left(\chi^{2}=13.1, \mathrm{p}=0.004\right.$ and $\chi^{2}=19.2$, $\mathrm{p}=0.0002$, respectively). This indicates that not only BEN patients differ from the healthy Bulgarian population but also Bulgarians per se have frequencies different from Germans for the most common MDR 1 haplotypes.

Individuals with assumed haplotype 12 were less frequent in BEN cases (frequency 7.3\%) than in controls $(16.1 \%, p=0.006)$ and carriers of the haplotype 12 showed lower risk for BEN $(\mathrm{OR}=0.411 ; 0.21-0.78)$.

\section{Discussion}

BEN is a tubulointerstitial disease, which is usually asymptomatic, leading to tubular atrophy, extensive fibrosis, chronic renal failure and loss of nephron mass. Up to $40 \%$ develop urinary tract tumors. The mosaic topographical distribution of the disease and incidence only in rural loci suggested that the occurrence of BEN is linked to the chemistry or microbiology of the environment [7]. Different toxic agents are suspected to have an impact in BEN development, although they were not convincingly implicated in the etiology of BEN [7, 8, 17-19]. The familial inheritance of BEN and the familial clustering of upper urinary tract tumors in BEN patients directed us to investigate the disease in genetic aspect [6].

The kidney, together with the liver and the intestine are the main excretory organs for the totally body clearance of various toxins and drugs. Extensive studies in the last years revealed the molecular basis of the transport mechanisms in the kidney and physiological events occurring in the nephron (filtration, secretion and reabsorption). $M D R 1$ transport activity plays a critical role in protecting against the toxic effects of exogenous compounds and drugs by mediating their excretion into urine. Disposition of these substrates presents genetically determined inter-individual variability [32]. Abnormal P-gp excretion of some xenobiotics and cationic compounds in the brush border membranes could be responsible for nephrotoxicity. $M D R 1$ variants with lower activity have been associated with renal tumors [23].

In the present study we determined the frequencies of two MDR 1 variants (C3435T and G2677T) and possible haplotypes in patients with BEN, supposing that they could have an association with nephropathy in BEN.

The estimated frequencies of the variant allele (2) for C3435T mutation were not significantly different in both groups (49\% in BEN group and 53\% in the controls). Similarly, as previously reported for Caucasians (48-54\%), C3435T was also fairly common in the Bulgarian population $[21,26]$. We found heterozygous carriers $(1 / 2)$ more 
frequently in BEN patients $(0.625)$ than in the healthy population $(0.420)$, but the homozygous genotype $(2 / 2)$ was less frequent in the patient group (0.177) compared to controls $(0.321)$. This argues against a gene-dose effect.

The observed frequencies of the variant allele (2) for G2677T in patients (0.469) and in the controls (0.438) were in accordance with the previous findings in Caucasians (0.424) [20]. Distribution of homozygous/heterozygous carriers of G2677T was similar in both groups.

Based on the differential effect of $M D R 1$ haplotypes on drug pharmacokinetics it was accepted that study on $M D R 1$ haplotypes was superior compared to SNP analysis to predict protein activity [22]. Therefore, the frequencies of haplotypes consisting of a combination of the two SNPs in BEN cases and controls were determined. MDR 1 haplotype analysis showed a lower frequency of haplotype 12 in the BEN group. This suggests that haplotype 12 is protective against BEN. The previous study demonstrated higher plasma levels of digoxin in carriers with at least one haplotype 12 in comparison to the non-carriers of this haplotype [22]. So far, there is no clear explanation for molecular mechanisms of haplotype to phenotype relationships. For example, the effects of identical haplotypes on oral digoxin pharmacokinetics varied when different ethnic groups were investigated [22, 31]. Further extended studies on the influence of different haplotypes on MDR 1 activity as well as a more detailed understanding of the molecular mechanism of renal excretion of suspected toxins are needed to determine molecular mechanisms for BEN development. A combination of several genes might be involved in gene-environment interactions.

The results of the present study lay the ground for more detailed analyses of polymorphisms in genes related to xenobiotic transport and detoxification, which may contribute to a genetic predisposing to BEN. Moreover, the expression levels of $M D R 1$ and other transporter genes in the kidney and tumor tissues from BEN have still not been investigated.

This study presents the first analysis of $M D R 1$ gene variants in a large sample of healthy Bulgarians and may be used as a database for Bulgarian population heterogeneity for future pharmacological investigations of $M D R 1$ dependent drugs.

\section{Acknowledgments}

This research was supported by Eurogendis, Marie-Curie Fellowship Foundation Contract N QLGA-CT-2000-60005 and INCOCopernicus Contract N IC15-CT98-0318 (DG 12-SNDR). We would like to thank Reiner Andag and Sandra Hartung for their excellent technical assistance.

\section{References}

1 Sattler T, Dimitrov T, Hall P: Relation between endemic (Balkan) nephropathy and urinary tract tumors. Lancet 1977;i:278.

2 Dimitrov T: Balkan endemic nephropathy in Bulgaria. Facta Universitatis 2002;9:7-14.

3 Bozić Z, Duancić V, Belicza M, Kraus O, Skliarov I: Balkan endemic nephropathy: Still mysterious disease. Eur J Epidemiol 1995; 11:235238.

4 Polenaković M, Stefanović V: Balkan nephropathy; in Davison A, Cameron J, Grunfeld J, Kerr D, Winerals G (eds): Oxford Textbook of Clinical Nephrology, ed 2. Oxford, Oxford University Press, 1997, vol 2, pp 1203-1211.

5 Mihailov T: New phenomena in the genealogical study of Balkan endemic nephropathy in Bulgaria; in Strahinjić S, Stefanović V (eds): Endemic (Balkan) nephropathy. Nis, University Press, 1979, pp 253-258.

6 Toncheva D, Dimitrov T, Stoyanova S: Etiology of Balkan endemic nephropathy: A multifactor disease. Eur J Epidemiol 1998;14:389-394.

7 Radovanović Z, Sindić M, Polenaković M, Dukanović L, Petronić V (eds): Endemic Nephropathy. Belgrad, Zavod za Udzbenike I Nastavna Sredstva, 2000, pp 1-200.
8 Stefanović V: Balkan endemic nephropathy: A need for novel aetiological approaches. Q J Med 1998;91:457-463.

9 Toncheva D, Dimitrov T: Genetic predisposition to Balkan endemic nephropathy. Nephron 1996;72:564-569.

10 Ernest S, Rajaraman S, Megyesi J, Bello-Reuss EN: Expression of MDR1 (multidrug resistance) gene and its protein in normal human kidney. Nephron 1997;77:284-289.

11 Sylvain E, Rajaraman S, Megyesi J, BelloReuss E: Expression of MDR1 (multidrug resistance) gene and its protein in normal human kidney. Nephron 1997;77:284-289.

12 Schinkel AH: The physiological function of drug-transporting P-glycoproteins. Semin Cancer Biol 1997;8:161-170.

13 Inui KI, Masuda S, Saito H: Cellular and molecular aspects of drug transport in the kidney. Kidney Int 2000;58:944-958.

14 Yeh GC, Lopaczynska J, Poore CM, Phang JM: A new functional role for P-glycoprotein: Efflux pump for benzo( $\alpha$ )pyrene in human breast cancer MCF-7 cells. Cancer Res 1992; 52:6692-6695.

15 Fardel O, Lecureur V, Guillouzo A: The P-glycoprotein multidrug transporter. Gen Pharmacol 1996;27:1283-1291.
16 Chin KV, Tanaka S, Darlington G, Pastan I, Gottesman MM: Heat shock and arsenite increase expression of the multidrug resistance (MDR1) gene in human renal carcinoma cells. J Biol Chem 1990;265:221-226.

17 Orem WH, Feder GL, Finkelnman RB: A possible link between Balkan endemic nephropathy and the leaching of toxic organic compounds from Pliocene lignites by groundwater. Int J Coal Geol 1999;40:3237-3252.

18 Voice T, McElmurry S, Long D, Petropoulos E, Ganev V: Evaluation of coal leachate contamination of water supplies as a hypothesis for the occurrence of Balkan endemic nephropathy in Bulgaria. Facta Universitatis Med Biol 2002;9: 123-130.

19 Wedeen P: Environmental renal disease: Lead, cadmium and Balkan endemic nephropathy. Kidney Int 1991;34(suppl):4-8.

20 Kim RB, Leake BF, Choo EF, Dresser GK, Kubba SV, Schwarz UI, Taylor A, Xie HG, McKinsey J, Zhou S, Lan LB, Schuetz JD, Schuetz EG, Wilkinson GR: Identification of functionally variant MDR1 alleles among European Americans and African Americans. Clin Pharmacol Ther 2001;70:189-199. 
21 Hoffmeyer S, Burk O, von Richter O, Arnold HP, Brockmöller J, Johne A, Cascorbi I, Gerloff T, Roots I, Eichelbaum M, Brinkmann U: Functional polymorphisms of the human multidrug-resistance gene: Multiple sequence variations and correlation of one allele with P-glycoprotein expression and activity in vivo. Proc Natl Acad Sci USA 2000;97:3473-3478.

22 Johne A, Köpke K, Gerloff T, Mai I, Rietbrock S, Meisel C, Hoffmeyer S, Kerb R, Fromm M, Brinkmann U, Eichelbaum M, Brockmöller, Cascorbi I, Roots I: Modulation of steady-state kinetics of digoxin by haplotypes of the P-glycoprotein MDR1 gene. Clin Pharmacol Ther 2002;72:584-594.

23 Siegsmund M, Brinkmann U, Schaffeler E, Weirich G, Schwab M, Eichelbaum M, Fritz P, Burk O, Decker J, Alken P, Rothenpieler U, Kerb R, Hoffmeyer S, Brauch H: Association of the P-glycoprotein transporter MDR1(C3435T) polymorphism with the susceptibility to renal epithelial tumors. J Am Soc Nephrol 2002;13:1847-1854.
24 Miller SA, Dykes DD, Polesky HF: A simple salting out procedure for extracting DNA from human nucleated cells. Nucleic Acids Res 1988; $16: 1215$.

25 von Ahsen N, Richter M, Grupp C, Ringe B, Oellerich M, Armstrong VW: No influence of the MDR-1 C3435T polymorphism or a CYP3A4 promoter polymorphism (CYP3A4$\mathrm{V}$ allele) on dose-adjusted cyclosporin A trough concentrations or rejection incidence in stable renal transplant recipients. Clin Chem 2001; 47:1048-1052.

26 von Ahsen N, Oellerich M, Armstrong VW, Schutz E: Application of a thermodynamic nearest-neighbor model to estimate nucleic acid stability and optimize probe design: Prediction of melting points of multiple mutations of apolipoprotein B-3500 and factor V with a hybridization probe genotyping assay on the LightCycler. Clin Chem 1999;45:2094-2101.

27 Terwillinger J, Ott J: Handbook of Human Genetic Linkage. Baltimore, Johns Hopkins University Press, 1994.
28 Xie X, Ott J: Testing linkage disequilibrium between a disease gene and marker loci. Am J Hum Genet 1993;53:1107.

29 Zhao H, Curtis D, Sham C: Model-free analysis and permutation test for allelic associations. Hum Hered 2000;50:133-139.

30 Bland JM, Altman D: The odds ratio. BMJ 2000;320:1468.

31 Kurata Y, Ieiri I, Kimura M, Morita T, Irie S, Urae A, Ohdo S, Ohtani H, Sawada Y, Higuchi S, Otsubo K: Role of human MDR1 gene polymorphism in bioavailability and interaction of digoxin, a substrate of P-glycoprotein. Clin Pharmacol Ther 2002;72:209-219.

32 Kerb R, Hoffmeyer S, Brinkmann U: ABC drug transporters: Hereditary polymorphisms and pharmacological impact in MDR1, MRP1 and MRP2. Pharmacogenomics 2001;2:5164. 